Gut, 1980, 21, 241-246

Clinical trial

\title{
Three year trial of endoscopic cytology of the stomach and duodenum*
}

\author{
JENNIFER A YOUNG† AND HELENA E HUGHES \\ From the Royal Infirmary, Glasgow
}

SUMmARY The results of endoscopic cytology during the period 1974 to 1976 are presented. These consist of a pilot study on 76 patients and a main trial on 329 patients, of whom 61 proved to have malignant disease as the final diagnosis. Methods of cell collection, preparation, and reporting are given. Special emphasis was placed on making a definitive diagnosis, especially the distinction between severe atypia and malignancy, and 'suspicious' reports were not issued. The overall accuracy achieved for all tumour types was $91.8 \%$, with an accuracy of $98 \%$ in the diagnosis of adenocarcinoma of the stomach. There were no false positive cytology reports. Endoscopic histology on the same patients gave an accuracy of $68.9 \%$ and did not give a positive result in any of the five cases with false negative cytology. Adequate sampling, a variety of cell collection methods, and great care in technique are necessary in order to obtain optimum sensitivity and specificity in cytological diagnosis.

Cancer of the stomach is a common condition with a high mortality. Lundh et al., ${ }^{1}$ in an international co-operative study (1974) found the overall four year survival rate in Europe to be less than $10 \%$. Determined efforts in Japan, where this disease is common, ${ }^{2}$ have led to remarkable improvements in diagnostic methods, the recognition of early gastric cancer, and increased survival rates. ${ }^{3}$ Diagnostic accuracies for cytology ranging from $85.7 \%$ to $\mathbf{9 6 . 0} \%$ have been reported by Kasugai and Kobayashi, ${ }^{4}$ using various methods of endoscopic cell collection. Prolla et al. ${ }^{5}$ achieved an overall accuracy of $84.7 \%$ in a series of 183 patients with cancer of the stomach and oesophagus, with $82.3 \%$ accuracy in 96 cases of adenocarcinoma of the stomach.

Although endoscopy and biopsy are widely practised in the United Kingdom only a few reports of the use of endoscopic cytology have appeared, ${ }^{6-9}$ Many of the problems associated with cytology of the digestive tract have arisen from the difficulty of distinguishing between benign atypical changes and malignancy, resulting in the issue of false positive or suspicious reports. This paper presents the results of a study in which an attempt was made to attain a high degree of sensitivity while maintaining a satisfactory level of specificity. Since sensitivity

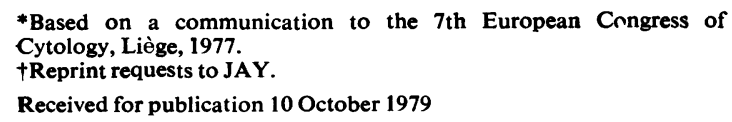

may be defined as 'the ability of the test to give a positive finding when the individual screened has the disease or abnormality under investigation'10 and specificity may be defined as 'the ability of the test to give a negative finding when the individual does not have the disease or abnormality under investigation'10 the achievement of high standards of sensitivity and specificity would, in practice, ensure diagnostic accuracy without false positive or suspicious reports.

\section{Methods}

The trial was divided into two parts, a pilot study and a main trial.

\section{PILOT STUDY}

The objectives of the pilot study were to establish methodology, assess the sensitivity and specificity obtainable by cytology, and to explore the importance of clinical information to the cytologist. Seventy-six patients were investigated. In 38 the cytology was read 'blind' without any knowledge of the radiological or endoscopic findings. These cases were selected by clinicians from a group of patients who were considered to present diagnostic difficulty and fulfilled at least one of the criteria in Table 1.

The other 38 cases were obtained by matching patients for age and sex with the 'blind' section 
Table 1 Indications for inclusion in 'blind' section of pilot study

\begin{tabular}{ll}
\hline & Indication \\
\hline 1 & Clinical suspicion of carcinoma \\
2 & Barium meal suggestive of carcinoma \\
3 & $X$-ray negative dyspepsia \\
4 & Gastric ulcer \\
\hline
\end{tabular}

cases. In this second group, known as the 'clinical' section, all diagnostic information, including the endoscopic findings, was available to the cytologist.

COLLECTION AND PREPARATION OF SPECIMENS Specimens were collected, by junior and senior medical staff, using Olympus endoscopes, generally Model GIF, Type D2, with standard brushes and forceps. The brushes were of the non-disposable type and could be withdrawn into a plastic sheath for removal from the endoscope. Brushing was carried out before the collection of biopsies. The type and number of specimens to be taken from each patient were left to the judgment of the clinician according to his endoscopic findings. Brushings were obtained from 37 patients in each section. Biposies were taken from all patients; the number varied from one to seven in the 'blind' section and from one to four in the 'clinical' section.

From four to six direct smears were made from each brush. During the early stages it became apparent that material remained adherent to the bristles after preparation of the direct smears. To obtain these cells the brush was placed in $5 \mathrm{~cm}^{3}(\mathrm{ml})$ normal saline and briskly agitated. Two Millipore filters were prepared from the resulting suspension. Six to nine touch smears for cytology were prepared from each biopsy, by the technique used in this laboratory. ${ }^{11}$ Paired biopsies, with and without preceding touch smears, were examined by pathologists, who observed no significant difference in the quality of the two biopsies. From each brush and biopsy all but one of the smears were rapidly fixed in $95 \%$ alcohol, while the remaining slide was air dried. The Millipore filters and three slides from each specimen were stained by the Papanicolaou technique. One slide from each set of touch smears was stained with Mucicarmine and one with Alcian Green and Yellow.

The air dried slides were all stained with MayGrunwald Giemsa. The remaining slides were left unstained for use as spare material, or for special, additional stains, if these were indicated.

\section{REPORTING}

All the cytology specimens were reported by the two authors and the responsibility for reporting was not delegated to other members of staff. At the outset, a decision was made not to issue 'suspicious' cytology reports. This policy was adopted to obtain a precise evaluation of the sensitivity and specificity of the results and an assessment of the reported difficulty in distinguishing between benign atypia and malignancy. ${ }^{12}$ It was decided to use a system of graded reporting based on the Papanicolaou classification ${ }^{13}$ developed for cervical cytology, but grade 3 , which is normally reserved for the 'suspicious' smear, was omitted. A descriptive report was issued for each specimen and for each patient a summary report stated categorically whether malignant cells were 'present' or 'not present'. The histology passed through the routine hospital service and was initially reported by a junior member of the medical staff, supervised by the consultant responsible for surgical routine at that time. As specimens were not always referred for the opinion of a pathologist with a special interest in gastrointestinal pathology occasional 'suspicious' histology reports were issued.

\begin{tabular}{cll} 
Table 2 & Grading system for gastric/duodenal cytology \\
\hline Grade 1 & Normal cells & \\
Grade 2 & Benign \\
A & Mild atypia & \\
B & Moderate atypia & \\
C & Severe atypia & Malignant \\
Grade 4 & Small number of malignant cells & \\
Grade 5 & Large number of malignant cells & \\
Grade U & Unsatisfactory & \\
\hline
\end{tabular}

MAIN TRIAL

All patients who had both endoscopic cytology and histology at the Royal Infirmary during the period 1974-76 entered the main trial. Specimens were received from 330 patients. One patient was excluded as he was lost to follow-up, leaving 329 with a definitive final diagnosis. Brushings were collected from 327 patients followed by biopsies in all 329 . The number of biopsies varied from one to seven. Touch smears were not made from the biopsies in two cases. The methods of specimen collection, preparation staining, and reporting were those established during the pilot study. Clinical information was available in the majority of cases.

\section{Results}

In both the pilot study and the main trial the final diagnosis of malignancy was verified in all cases by laparotomy, or additional biopsy or post-mortem examination. Where the final diagnosis was recorded as benign and both cytology and endoscopic histology were negative, the diagnosis rested on clinical follow-up, the minimum period being two years. 
Table 3 Results of 'blind' section of pilot study (38 cases)

\begin{tabular}{|c|c|c|c|c|}
\hline \multirow[t]{2}{*}{ Test result } & \multicolumn{2}{|c|}{ Final diagnosis } & \multirow{2}{*}{$\begin{array}{l}\text { Sensitivity } \\
(\%)\end{array}$} & \multirow{2}{*}{$\begin{array}{l}\text { Specificity } \\
(\%)\end{array}$} \\
\hline & Malignant & Benign & & \\
\hline \multicolumn{5}{|l|}{ Cytology } \\
\hline Malignant 12 & 12 & 0 & $85 \cdot 7$ & 100 \\
\hline Benign 26 & 2 & 24 & & \\
\hline \multicolumn{5}{|l|}{ Histology } \\
\hline Malignant 11 & 10 & 1 & $71 \cdot 4$ & $90 \cdot 9$ \\
\hline Benign $\quad 27$ & 4 & 23 & & \\
\hline
\end{tabular}

Where there was a discrepancy between the cytology and the endoscopic histology the final benign diagnosis was established by laparotomy and histology of resected tissue. The results of cytology and histology were analysed for sensitivity and specificity.

The results of the two sections of the pilot study and of the main trial are shown in Tables 3, 4, and 5 . In the main trial, in order to make a valid comparison of the practical value of the two techniques, the four patients with 'inadequate' histology were considered as 'showing no evidence of malignancy' and were grouped with the benign cases. Adequate cytology specimens were obtained from all four

Table 4 Results of 'clinical' section of pilot study (38 cases)

\begin{tabular}{|c|c|c|c|c|}
\hline \multirow[t]{2}{*}{ Test result } & \multicolumn{2}{|c|}{ Final diagnosis } & \multirow{2}{*}{$\begin{array}{l}\text { Sensitivity } \\
(\%)\end{array}$} & \multirow{2}{*}{$\begin{array}{l}\text { Specificity } \\
(\%)\end{array}$} \\
\hline & Malignant & Benign & & \\
\hline \multicolumn{5}{|l|}{ Cytology } \\
\hline Malignant 6 & 6 & 0 & 100 & 100 \\
\hline Benign $\quad 32$ & 0 & 32 & & \\
\hline \multicolumn{5}{|l|}{ Histology } \\
\hline Malignant 3 & 3 & 0 & 50 & 100 \\
\hline Benign $\quad 35$ & 3 & 32 & & \\
\hline
\end{tabular}

Table 5 Results of main trial (329 cases)

\begin{tabular}{|c|c|c|c|c|}
\hline \multirow[t]{2}{*}{ Test result } & \multicolumn{2}{|c|}{ Final diagnosis } & \multirow{2}{*}{$\begin{array}{l}\text { Sensitivity } \\
(\%)\end{array}$} & \multirow{2}{*}{$\begin{array}{l}\text { Specificity } \\
(\%)\end{array}$} \\
\hline & Malignant & Benign & & \\
\hline 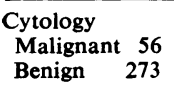 & $\begin{array}{r}56 \\
5\end{array}$ & $\begin{array}{r}0 \\
268\end{array}$ & $91 \cdot 8$ & 100 \\
\hline $\begin{array}{l}\text { Histology } \\
\text { Malignant } 43 \\
\text { Benign* }^{*} 286\end{array}$ & $\begin{array}{l}42 \\
19\end{array}$ & $\begin{array}{r}1 \\
267\end{array}$ & $68 \cdot 9$ & $97 \cdot 6$ \\
\hline
\end{tabular}

*Including: suspicious 7 , inadequate 4. patients. The final diagnosis was malignant in one of these cases. Of the seven patients with 'suspicious' histology, four were eventually proved benign and three malignant. If the 'inadequate' cases are deleted and the 'suspicious' cases added to those with positive histology, the sensitivity of the histology increases to $75 \%$, but there is a corresponding rise from one to five in the number of false positive and false 'suspicious' reports.

An analysis of the accuracy of the various cytology methods for the 61 malignant cases is given in Table 6. While a positive result was obtained from all specimens in 27 cases $(48.2 \%)$ in the remaining 29 cases $(51.8 \%)$, one or more specimens gave a negative result.

Table 7 Analysis of cell collection methods in 14 malignant cases with positive cytology and false negative endoscopic histology

Brush positive
Biopsy touch smears positive
Overall cytology positive

Overall cytology positive

Table 8 Diagnostic yield of cell collection methods in 14 malignant cases with positive cytology and false negative endoscopic histology

Brush positive/biopsy touch smear negative 4 Brush negative/biopsy touch smear positive 2

Brush positive/biopsy touch smear positive 8

Tables 7 and 8 analyse the diagnostic yield for the various methods of cell collection for the 14 malignant cases with positive cytology and false negative endoscopic histology. It is interesting to note that touch smear cytology was positive from at least one biopsy in 10 of these patients.

The results for cytology and histology, according to site and tumour type, are shown in Table 9. The sensitivity of cytology in the stomach was $92.7 \%$, with $98 \%$ for adenocarcinoma. The figures for histology were $70.9 \%$ for all tumours of the stomach and $75.5 \%$ for adenocarcinoma. The single patient with adenocarcinoma of the stomach and false negative cytology was extremely ill at the time of endoscopy and died four days later. While cytological diagnosis of the more uncommon types of

Table 6 Analysis of cytology methods in 61 malignant cases

\begin{tabular}{|c|c|c|c|c|c|}
\hline \multirow[t]{2}{*}{ Method } & \multicolumn{4}{|c|}{ Cytology results } & \multirow{2}{*}{$\begin{array}{l}\text { Sensitivity } \\
(\%)\end{array}$} \\
\hline & Malignant & Benign & Unsatisfactory & Not done & \\
\hline Brush/direct smears & 49 & 10 & 1 & 1 & $81 \cdot 6$ \\
\hline Brush/saline & 44 & 12 & 4 & 1 & $73 \cdot 3$ \\
\hline Biopsy touch smears & 51 & 8 & 0 & 2 & $86 \cdot 4$ \\
\hline Overall cytology & 56 & 5 & 0 & 0 & $91 \cdot 8$ \\
\hline
\end{tabular}


Table 9 Cytology and histology results in relation to final diagnosis by site and tumour type

\begin{tabular}{|c|c|c|c|c|c|}
\hline \multirow{2}{*}{$\begin{array}{l}\text { Site and final diagnosis } \\
\text { tumour type }\end{array}$} & \multirow{2}{*}{ Number of cases } & \multicolumn{2}{|l|}{ Cytology } & \multicolumn{2}{|l|}{ Histology } \\
\hline & & Malignant & Benign & Malignant & Benign \\
\hline \multicolumn{6}{|l|}{ Stomach } \\
\hline Adenocarcinoma & 49 & $48(98.0 \%)$ & 1 & $37(77.5 \%)$ & 12 \\
\hline Anaplastic carcinoma & 2 & 1 & 1 & 1 & 1 \\
\hline Sarcoma & 2 & 0 & 2 & 0 & 2 \\
\hline Lymphoproliferative disorder & 2 & 2 & 0 & 1 & 1 \\
\hline Total & 55 & $51(92 \cdot 7 \%)$ & 4 & $39(70.9 \%)$ & 16 \\
\hline \multicolumn{6}{|l|}{ Duodenum } \\
\hline Adenocarcinoma & 1 & 1 & 0 & 1 & 0 \\
\hline Lymphoproliferative disorder & 1 & 1 & 0 & 1 & 0 \\
\hline Total & 2 & 2 & $\mathbf{0}$ & 2 & 0 \\
\hline \multicolumn{6}{|l|}{ Pancreas } \\
\hline Adenocarcinoma & 4 & 3 & 1 & 1 & 3 \\
\hline \multicolumn{6}{|l|}{ All sites } \\
\hline All types & 61 & $56(91 \cdot 8 \%)$ & 5 & $42(68.9 \%)$ & 19 \\
\hline
\end{tabular}

malignancy was less successful, the lymphoproliferative lesions were identified and, somewhat surprisingly, three out of the four pancreatic carcinomas yielded diagnostic malignant cells. The malignant cells were seen in brushings of the duodenal wall in two of the pancreatic tumours and touch smears of two duodenal wall biopsies were additionally positive in one of these cases. Brush cytology of the pylorus was positive in the third patient. Only one of the cases of pancreatic carcinoma was diagnosed by endoscopic histology. Neither of the cases of leiomyosarcoma was diagnosed, but this can be attributed to the difficulty of obtaining a diagnostic sample from any submucosal lesion.

\section{Discussion}

\section{PILOT STUDY}

The results of the pilot study showed that the accuracy achieved by the cytology programme was higher than that of routine endoscopic histology. This higher level of sensitivity was obtained without loss of specificity, as no false positive or 'suspicious' cytology reports had been issued. The superiority of cytology was demonstrated in both sections of the study, but the advantage was more marked in the 'clinical' section. The knowledge of clinical findings -and especially whether peptic ulceration was present or not-was found helpful in interpretation of the cytology. Both brush and biopsy touch smear preparations contributed to the correct cytology results in the five patients with positive cytology and false negative histology. It was therefore decided to continue with a variety of cytology techniques for the main trial, to assess further the potential of the different methods. Although the distinction between benign atypia and malignancy had been made successfully the differentiation was often difficult, as there was considerable overlap between the cellular characteristics of severe atypia (grade 2C) and malignancy. It was apparent that a larger study and follow-up of patients with grade $2 \mathrm{C}$ cytology was necessary.

\section{MAIN TRIAL}

The accuracy of cytology for the 61 malignant cases in the complete trial was $91.8 \%$, which was $22.9 \%$ higher than the histology results. Fortynine of the 61 tumours were adenocarcinomas of the stomach and the diagnostic accuracy of cytology in this group was $98 \%$, an increase of $22.5 \%$ over the histology. The analysis of the different methods of cell collection and preparation underlines the importance of using all the cellular material obtainable by a variety of techniques to obtain optimal results. The single most accurate method was the biopsy touch smear. The sensitivity of this test was $86.4 \%$ overall and, surprisingly, it yielded a positive result in 10 of the 19 patients with false negative endoscopic histology. Furthermore, it was the only cytological technique which gave the correct malignant diagnosis in two of these patients. This increase in sensitivity due to the use of touch smears as a procedure complementary to biopsy is similar to the findings of Japanese cytologists. ${ }^{14-16}$ This technique is especially useful in the examination of necrotic material, when malignancy can sometimes be recognised at a 'cellular level' even though the specimen is inadequate for histological diagnosis. Brush cytology was the only method which gave a positive result in four of the patients with false negative histology. Although the overall sensitivity of the direct smears $(81.6 \%)$ was higher than that of the saline suspension $(73.3 \%)$, in one of the four cases the latter technique was the only method which yielded malignant cells. 
Table 10 Characteristics of atypical and malignant epithelial cells of stomach

\begin{tabular}{|c|c|c|c|c|c|}
\hline \multirow[t]{2}{*}{ Characteristic } & \multicolumn{3}{|c|}{ Atypical cells } & \multirow{2}{*}{\multicolumn{2}{|c|}{ Malignant cells }} \\
\hline & $2 A$ & $2 B$ & $2 C$ & & \\
\hline Variation in nucleocytoplasmic ratio & $\div$ & $\ldots$ & $+\frac{1}{1}$ & +1 & $\longrightarrow++t+$ \\
\hline Anisonucleosis & + & +- & $+t+$ & $-\ldots$ & $\longrightarrow++t+$ \\
\hline Anisochromasia & + & +4 & $+\ldots$ & $+\cdot \cdot$ & $\longrightarrow+t+t$ \\
\hline Enlarged nucleoli & + & $\ldots$ & $+\ldots$ & $\cdots$ & $\longrightarrow \longrightarrow+\div+$ \\
\hline Nuclear pleomorphism & - & + & $-\because$ & .. & $\longrightarrow+++$ \\
\hline Normal mitotic figures & - & - & $T$ & 一 & $\longrightarrow+$ \\
\hline Reduction of intercellular cohesion & - & $\ldots$ &..+ & $\rightarrow \cdots$ & $\longrightarrow+\cdots+$ \\
\hline Cytoplasmic vacuolation & - & + & - & 一 & $\longrightarrow \longrightarrow+++$ \\
\hline Abnormal mitotic figures & - & - & - & - & $\longrightarrow+$ \\
\hline Increase in nuclear density & - & - & - & - & $\longrightarrow+++t$ \\
\hline Altered intercellular pattern & 一 & - & + & - & $\longrightarrow++++$ \\
\hline
\end{tabular}

Exploration of the distinction between severe benign atypia and malignancy was one of the features of the trial. The differentiation between the two is difficult and our experience is not in accordance with the opinion in the report of the Medical Research Council ${ }^{17}$ that "brush specimens collected at endoscopy are relatively simple to collect, prepare and interpret'. There is no single cellular characteristic that can be used on its own to separate severe atypia (grade 2C) from malignancy (grades 4 and 5). The cellular characteristics which we found most helpful are shown in Table 10.

It can be seen that there is considerable variation both in the incidence and the degree to which abnormal features are present in malignant specimens, as no two malignant cases are the same. Although, in many instances, a single individual characteristic abnormality may be present to such a marked degree that the diagnosis of malignancy is obvious, in other cases the same characteristic may be completely absent. In our experience, the most helpful feature in distinguishing severe atypia from malignancy is alteration of intercellular pattern-not only alteration of cellular polarity within the groups, but also the pattern of distribution of the cells on the slide as a whole. If abnormal mitotic figures can be identified with certainty they are a clear indication of malignancy, but this occurs in only occasional specimens. Mitotic figures themselves, however, are not infrequently seen, especially in cells from the regenerating edge of gastric ulcers and the separation of normal from abnormal forms is not easy, with routine light microscopy. The presence of mitotic figures is a known cause of false positive reports ${ }^{18}$ in gastric cytology and care must be taken in the interpretation of their significance.

Follow-up of the 329 patients in the trial shows that the distinction between severe atypia and malignancy was made successfully, with the possible exception of one case where the tumour was of pancreatic origin. In 268 cases the final diagnosis was benign. Fifty-two of these patients showed severe atypia (grade 2C) on cytology, but none has shown any evidence of malignancy on a followup of between two and four years. Ten of these patients have undergone surgery for benign conditions and another 12 have had an additional endoscopy with negative biopsy. Of the remaining 30 , 29 are alive and well and one, in whom the diagnosis was gastric sarcoidosis, has died from unrelated causes. Five of the 61 eventually malignant cases had false negative cytology. Only one of these had been reported cytologically as severe atypia (grade $2 \mathrm{C}$ ), with four cases reported as moderate atypia (grade 2B). These gradings remained unchanged when the slides were reviewed in the light of the final diagnoses. The patient with grade $2 \mathrm{C}$ cytology died three months later and at necropsy was found to have a carcinoma of the pancreas invading the duodenal wall. Two of the grade $2 \mathrm{~B}$ cases were found to have leiomyosarcomas on examination of operative specimens. Omental biopsy in the third case showed anaplastic carcinoma of probable gastric origin. The fourth patient was the one previously described, who died four days after endoscopy and a $7 \mathrm{~cm}$ ulcerated adenocarcinoma of the pyloric area was found at necropsy. All these five patients also had false negative endoscopic histology. This suggests that failure to reach a positive diagnosis was due to sampling error rather than misinterpretation of cytological material. The importance of the precise site of collection as well as the number of specimens was shown by Hatfield et al. ${ }^{19}$ with regard to the accuracy of endoscopic biopsy in ulcerating lesions of the stomach. The combination of brush and touch smear cytology with biopsy, by maximum use of all available material, can help to reduce, but does not eliminate, the difficulty of correct sampling at the time of endoscopy.

\section{Conclusion}

From this study, we form the same opinion as Prolla et al. ${ }^{5}$ that 'meticulous care in technique is 
needed'. Adequate sampling and a variety of cell collection and processing methods are required to obtain optimal sensitivity and specificity. Examination of the necessary specimens may sometimes be both time-consuming and difficult, but despite these reservations we feel that cytology is a valuable aid to the diagnosis of malignancy in the stomach and duodenum and deserves to be more widely practised as an adjunct to endoscopy.

The authors would like to thank the many people who participated in this trial, especially Professor L Blumgart, Mr S Joffe, Dr R Russell and Dr J MacKenzie and their staff, who referred patients and collected specimens; Professor R Goudie, Dr F Lee, and the staff of the Pathology Department for the histology; and Mr G Campbell for technical assistance. This work forms part of a project supported by a grant from the Scottish Home and Health Department.

\section{References}

${ }^{1}$ Lundh G, Burn JI, Kolig G et al. A co-operative international study of gastric cancer. Ann $R$ Col Surg Engl 1974; 54: 219-28.

${ }^{2}$ World Health Organization. World health statistics annual: Vol 1. Geneva: WHO, 1976: 388-95.

${ }^{3}$ Kaneko E, Nakamura T, Umeda N, Fujino M, Niwa H. Outcome of gastric carcinoma detected by gastric mass survey in Japan. Gut 1977; 18: 626-30.

${ }^{4}$ Kasugai T, Kobayashi S. Evaluation of biopsy and cytology in the diagnosis of gastric cancer. Am J Gastroenterol 1974: 62: 199-203.

${ }^{5}$ Prolla JC, Reilly W, Kirsner JB, Cockerham L. Direct vision endoscopic cytology and biopsy in the diagnosis of esophageal and gastric tumours: current experience. Acta Cytol 1977; 21 : 399-402.

${ }^{6}$ Gwyn Williams D, Truelove SC, Gear MWL, Massarella GR, Fitzgerald NW. Gastroscopy with biopsy and cytological sampling under direct vision. $\mathrm{Br}$ Med $J$ 1968; 1: 535-9.
'Boddington MM. Upper gastrointestinal endoscopythe cytologists viewpoint. In: Truelove SC, Trowell J, eds. Topics in gastroenterology 2. Oxford: Blackwell Scientific Publications, 1975: 45-51.

${ }^{8}$ Smithies A, Lovell D, Hishon S et al. Value of brush cytology in diagnosis of gastric cancer. Br Med J 1975; 4 : 326.

${ }^{9}$ Keighley MRB, Thompson H, Moore J, Hoare AM, Allan RN, Dykes PW. Comparison of brush cytology before or after biopsy for diagnosis of gastric carcinoma. Br J Surg 1979; 66: 246-7.

${ }^{10}$ Cochrane AL, Holland WW. Validation of screening procedures. $\mathrm{Br}$ Med Bull 1971; 27 : 3-8.

${ }^{11}$ Hughes HE, Lee FD, MacKenzie JF. Endoscopic, cytology and biopsy in the upper gastrointestinal tract. Clin Gastroenterol 1978; 7: 375-96.

${ }^{12}$ Richards WCD, Spriggs AI. The cytology of gastric mucosa. J Clin Pathol 1961 ; 14 : 132-9.

${ }^{13}$ Papanicolaou GH. Criteria of malignancy. In: Atlas of exfoliative cytology. Cambridge, Mass. Harvard University Press, 1954: 13-21.

${ }^{14}$ Yoshii Y, Takahashi J, Yamaoka Y, Kasugai T. Significance of imprint smear in cytologic diagnosis of malignant tumours of the stomach. Acta Cytol 1970; 14: 249-53.

${ }^{15}$ Yamakawa T, Panish J, Berci G et al. The correlation of target biopsy and contact smear cytology under direct visual control in malignant gastric lesions. Gastrointest Endosc 1971; 17: 164-8.

${ }^{16}$ Tamura K, Masuzawa M, Akiyama T, Fukui O. Touch smear cytology for endoscopic diagnosis of gastric carcinoma. Am J Gastroenterol 1977; 67: 463-7.

${ }^{17}$ Medical Research Council. Review of gastric and colorectal cancers. Report by Steering Group of Conference in Edinburgh, April 2-3, 1977. London: Medical Research Council, 1977: 14.

${ }^{18}$ Kobayashi S, Prolla JC, Kirsner JB. Brushing cytology of the esophagus and stomach under direct vision by fibrescopes. Acta Cytol 1970; 14: 219-23.

${ }^{19}$ Hatfield ARW, Slavin G, Segal AW, Levi AJ. Importance of the site of endoscopic gastric biopsy in ulcerating lesions of the stomach. Gut 1975; 16: 884-6. 